\title{
Combined supra/infratentorial-transsinus approach to large pineal region tumors
}

Ibrahim M. Ziyal, M.D., Laligam N. Sekhar, M.D., Eduardo Salas, M.D., and Wayne J. Olan, M.D. Departments of Neurosurgery and Radiology, The George Washington University Medical Center, Washington, D.C.

Object. The authors sought to confirm that the combined supra/infratentorial-transsinus approach offers a safer means of resecting large pineal region tumors than other approaches currently being used. The aforementioned method provides a wider exposure of the pineal region with less brain retraction than the infratentorial-supracerebellar or the occipital-transtentorial approach alone and is applicable to some large and giant tumors of this area. This combined approach was used in six patients to remove large pineal region tumors including four tentorial meningiomas, one pineocytoma, and one epidermoid cyst.

Methods. The transverse sinus and tentorium were sectioned after review of preoperative angiographic studies, after taking intraoperative measurements of the venous pressure in the nondominant transverse sinus before and after clipping and while monitoring the somatosensory evoked potentials. The occipital lobe cortex and cerebellum were retracted slightly along the tentorium. Deep veins of the galenic system, the quadrigeminal area, and the tumor were well exposed. Before it was used for tumor resection the approach was studied in five cadaveric head specimens, and the projection of different approaches was compared radiologically.

The tumors were removed in a gross-total manner in all patients, and none of the major veins of the galenic system was injured. Resuturing of the nondominant transverse sinus was performed postoperatively in one patient. One of the six patients experienced transient visual loss, and another suffered mild right sixth cranial nerve paresis; however, both recovered in 3 weeks. The wide exposure of the combined approach was also confirmed on radiological and anatomical studies.

Conclusions. The combined supra/infratentorial-transsinus approach is preferred for the resection of certain large pineal region tumors.

\section{Key Words * pineal region tumor * surgical approach * supra/infratentorial-transsinus approach}

In the past, the deep location of pineal region tumors and their relationships with important anatomical structures have resulted in significant operative morbidity and mortality rates.[7,8,34] These unsuccessful surgical results prompted neurosurgeons to develop safer approaches for removing pineal region tumors. The transcallosal, occipital-transtentorial, and infratentorial-supracerebellar approaches have been developed and used successfully in this area.[2,4,6,11,16,17,25,35] The combined supra/infratentorial-transsinus approach for the removal of a large tentorial meningioma was reported 
previously by Sekhar and Goel[27] in 1992, and since that time this approach has been used successfully in six patients with giant tumors of the pineal region.

\section{CLINICAL MATERIAL AND METHODS}

\section{Patient Population}

During a 5-year period, six patients (five women and one man) underwent surgery in which the combined supra/infratentorial-transsinus approach was used. The most frequent presenting symptoms were headache and gait difficulty. All patients had giant $(>4.5 \mathrm{~cm})$ tumors of the pineal or posterior tentorial notch region: four tentorial meningiomas, one pineocytoma, and one epidermoid cyst (Table 1). The new approach was selected when the tumor arose from the tentorium or extended well above and below the tentorial notch. After performing preoperative angiographic studies, intraoperative monitoring of venous blood flow, and measuring somatosensory evoked potentials (SSEPs), we sectioned the nondominant transverse sinus (usually the left side).

\begin{tabular}{|c|c|c|c|c|c|c|c|c|}
\hline & & INICAL CHARACTEF & $\begin{array}{l}\text { TA } \\
\text { TKS OF SIX PATIENTS } \\
\text { JPRAMIINFRATENTORIAL }\end{array}$ & $\begin{array}{l}\text { BLE } 1 \\
\text { WITH PINE } \\
\text { L-TRANSS I }\end{array}$ & $\begin{array}{l}\text { EAL REGON } \\
\text { NUS APPRO }\end{array}$ & TUMORS TREA] & VIA THE & \\
\hline $\begin{array}{l}\text { Case } \\
\text { No. }\end{array}$ & $\begin{array}{l}\text { Age } \\
\text { (y } \text { Sex }^{\prime} \text {, }\end{array}$ & Symptom & $\begin{array}{c}\text { Tum or Type \& } \\
\text { Size (cm) }\end{array}$ & $\begin{array}{l}\text { Preop Hydr } \\
\text { \& VP } \\
\text { Shurking }\end{array}$ & Sinus & Complications & $\begin{array}{l}\text { Follow } \\
\text { Upt }\end{array}$ & Ottcomef \\
\hline 1 & $47, F$ & $\begin{array}{l}\text { headache, gait } \\
\text { difficulty }\end{array}$ & $\begin{array}{l}\text { tentorial meningi- } \\
\text { oma }(5 \times 6 \times 7)\end{array}$ & - & It & $\begin{array}{l}\text { transient } \\
\text { visual loss }\end{array}$ & $31 \mathrm{mos}$ & $\begin{array}{l}\text { working, } \\
90\end{array}$ \\
\hline 2 & $21, F$ & $\begin{array}{l}\text { headache, ear- } \\
\text { ly eye signs }\end{array}$ & $\begin{array}{l}\text { epidermoid tumor } \\
(4 \times 4 \times 4.5)\end{array}$ & + & It & none & $36 \mathrm{mos}$ & $\begin{array}{l}\text { working, } \\
100\end{array}$ \\
\hline 3 & $48, F$ & headache & $\begin{array}{l}\text { tentorial meningi- } \\
\text { oma } 3 \times 4 \times 6)\end{array}$ & + & $\mathrm{rt}$ & none & $42 \mathrm{mos}$ & $\begin{array}{l}\text { working, } \\
100\end{array}$ \\
\hline 4 & $41, F$ & $\begin{array}{l}\text { headache, gait } \\
\text { difficulty dou- } \\
\text { ble vision }\end{array}$ & $\begin{array}{l}\text { pineocytoma } \\
(3 \times 3.5 \times 4)\end{array}$ & + & It & $\begin{array}{l}\text { shunt dys- } \\
\text { function }\end{array}$ & $41 \mathrm{mos}$ & $\begin{array}{l}\text { working, } \\
90\end{array}$ \\
\hline 5 & $69, F$ & $\begin{array}{l}\text { headache, con- } \\
\text { fusion }\end{array}$ & $\begin{array}{l}\text { tentorial meningi- } \\
\text { oma }(3 \times 3.5 \times 4.5)\end{array}$ & + & It & none & $55 \mathrm{mos}$ & $\begin{array}{l}\text { working, } \\
90\end{array}$ \\
\hline 6 & $45, M$ & $\begin{array}{l}\text { loss of balance, } \\
\text { hearing loss, } \\
\text { mental dist }\end{array}$ & $\begin{array}{l}\text { tentorial meningi- } \\
\text { oma }(4 \times 4.5 \times 5)\end{array}$ & + & $\begin{array}{l}\text { It (resu- } \\
\text { tured) }\end{array}$ & $\begin{array}{l}\text { mild, rt } \\
\text { CN vi } \\
\text { paresis }\end{array}$ & $82 \mathrm{mos}$ & $\begin{array}{l}\text { working, } \\
90\end{array}$ \\
\hline
\end{tabular}

\section{Preoperative Studies}

Magnetic resonance (MR) imaging revealed information about tumor localization and extension, and its relation to the tentorial notch. Magnetic resonance angiography revealed the size, dominance, and collateralization of the transverse sinuses, which are important factors in planning the combined approach. Cerebral angiography provided information about the deep venous system, the vein of Galen, the internal cerebral veins, the basal vein of Rosenthal, the superficial venous system, the patency of the straight sinus, and the collateralization and enlargement of the normally present sinus (for example, the inferior sagittal sinus). Using angiography we were able to delineate the vascularity of the lesion and its relationship to the various arteries and veins in the area. If division of the transverse sinus was planned, the existence of good communication between the transverse sinuses in the region of the torcular herophili was established on preoperative studies. 
If the patient was diagnosed as having significant obstructive hydrocephalus preoperatively, a ventriculoperitoneal (VP) shunt was usually placed before the tumor operation.

\section{Anesthesia and Monitoring}

Anesthesia was induced by using standard endotracheally administered thiopental and a short-acting muscle relaxant in all patients. Furosemide and/or mannitol were administered intravenously at the start of the operation. A precordial Doppler device was placed to detect air emboli, and a right atrial catheter was inserted to monitor the central venous pressure and to aspirate air in the event of an embolism. Prophylactic antibiotic drugs were administered intravenously.

The SSEPs were monitored continuously during the operation. Stimulating electrodes were placed bilaterally at the median nerve in the wrist, and recording electrodes were placed over the appropriate somatosensory cortex. Bilateral brainstem auditory evoked responses were similarly monitored during the operation. Transit-time Doppler flow measurements were obtained by means of a 3-mm probe.

\section{Operative Technique}

The patient was placed in a semiprone position, which is preferred for this approach because the surgeon can sit behind the patient (Fig. 1). We placed the side of the proposed transverse sinus section inferiorly, which allows for gravity-aided retraction of the occipital lobe. A U-shaped incision was made, and the skin flap and muscles were elevated as a single layer. The craniotomy was usually performed in three pieces, and the first plate removed was the suboccipital (Fig. 2A). After separating the transverse sinus under tangential vision, an occipital craniotomy was performed on one side up to the superior sagittal sinus (SSS) (Fig. 2B). After separating the SSS from the bone under direct vision, we were able to perform the occipital craniotomy on the other side more safely (Fig. 2C) because this technique avoids injuries to the venous sinuses.

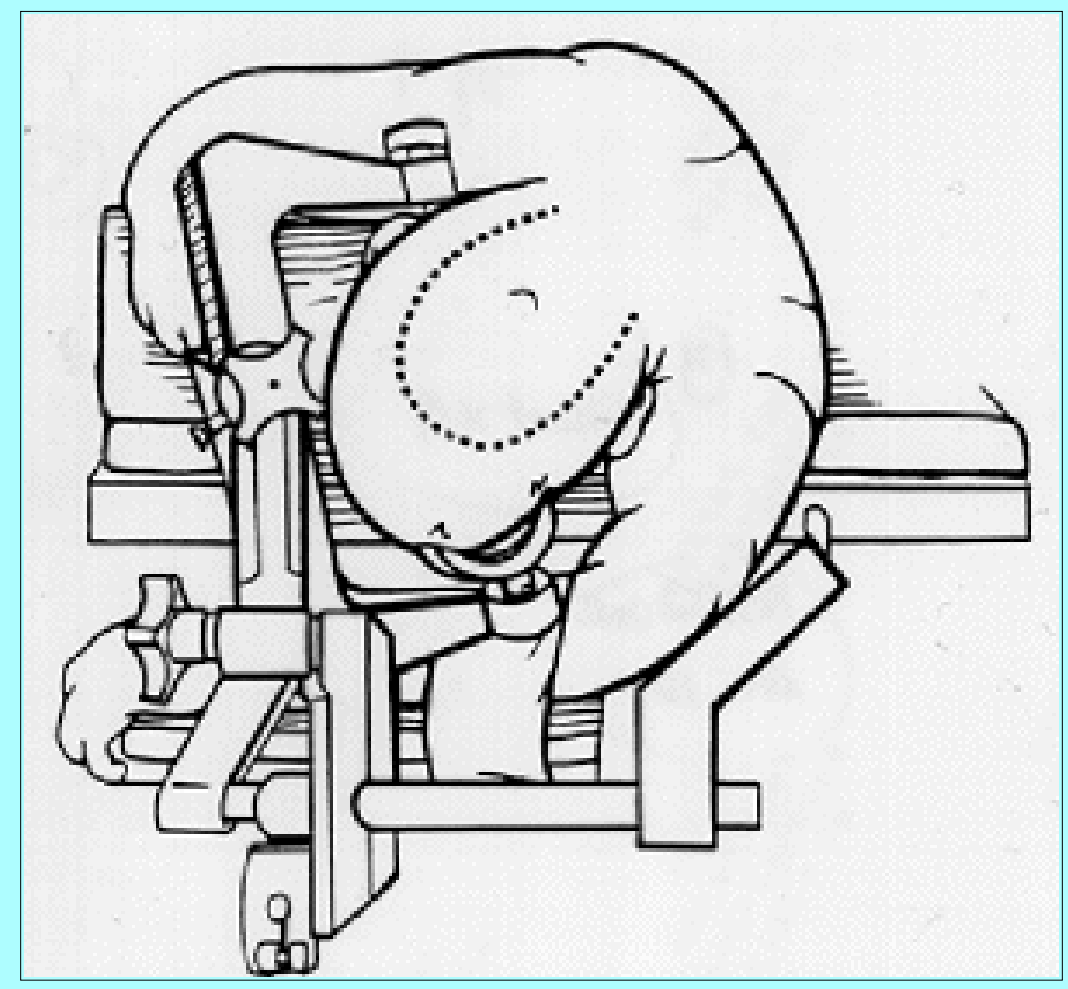

Fig. 1. Drawing showing the semiprone position, which is preferred for the combined approach. The dashed line indicates the U-shaped incision. This position allows the surgeon 
to sit behind the patient.

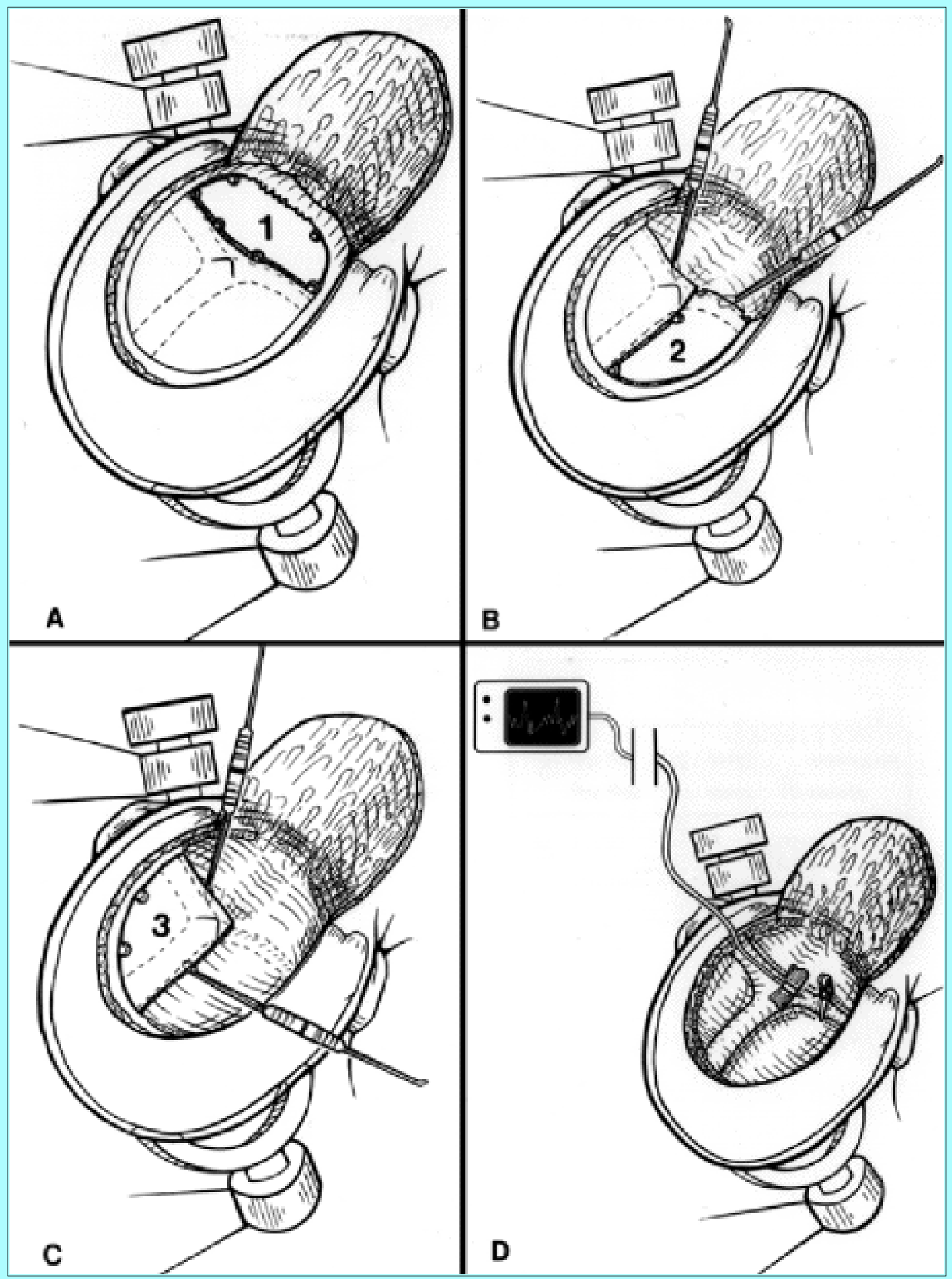

Fig. 2. Drawings showing the procedure. A: The craniotomy is usually performed in three pieces, with the suboccipital plate removed first. B: After separating the transverse sinus under tangential vision, an occipital craniotomy is performed on one side, up to the SSS. C: After separating the SSS from the bone, the occipital craniotomy is performed on the other side. D: The suboccipital dura is opened in a transverse fashion just inferior to the transverse 
sinus. The occipital dura is then opened parallel to the venous sinuses on the inferior side. A 20-gauge butterfly needle attached to a manometer is placed in the transverse sinus just lateral to the torcular herophili, where test occlusion of the sinus is performed by using a temporary clip lateral to the needle. $1,2,3=$ order in which the plates were removed.

The suboccipital dura was opened in a transverse fashion just inferior to the transverse sinus, dividing the occipital sinus if necessary. The cisterna magna was opened to permit relaxation of the brain through a small dural incision. The occipital dura was then opened on the inferior side, medial to the SSS and superior to the transverse sinus. The safety of division of the nondominant transverse sinus was then established in the following manner: a 20-gauge butterfly needle was attached to a manometer and was inserted into the transverse sinus just lateral to the torcular herophili, and test occlusion of the sinus lateral to the needle was continued for 5 minutes. If the venous pressure does not rise more than $5 \mathrm{~mm}$ $\mathrm{Hg}$ during this test, if no brain swelling is observed, and if there are no changes in the SSEPs, the nondominant transverse sinus can be sectioned safely (Fig. 2D). In that event, the sinus was clipped with two temporary clips and divided (Fig. 3 left). The tentorium was then cut just lateral to the straight sinus and toward the tentorial notch area. The occipital lobe and the cerebellum were gently retracted to expose the quadrigeminal region (Fig. 3 right).

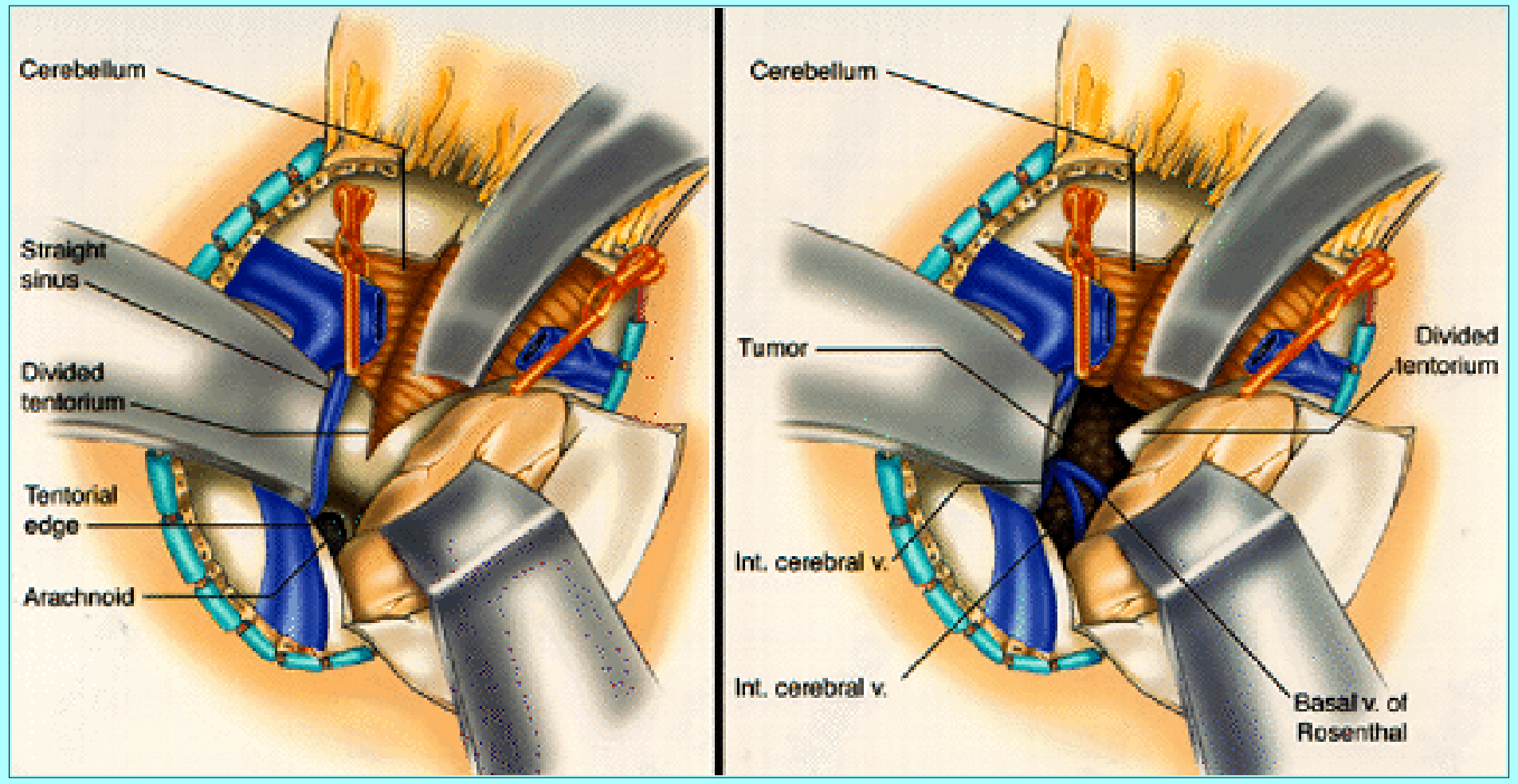

Fig. 3. Artist's drawing of a combined supra/infratentorial-transsinus approach to a large pineal region tumor. Left: The nondominant transverse sinus has been clipped with two temporary clips and divided. The occipital lobe and the cerebellum are gently retracted to expose the tentorium. Right: The tentorium is then cut just lateral to the straight sinus and toward the tentorial notch area. The wide exposure of the tumor is seen together with important venous structures. Int. $=$ internal; v. $=$ vein .

The excision of the tumor was accomplished in the usual fashion. If deep venous structures were found to be encased, they were carefully dissected and preserved. After removal of the tumor, the transverse sinus can be sutured with 5-0 or 6-0 prolene. If such reconstruction is preferred, a short vein graft may be necessary because the dura containing the sinuses shrinks during the operation. 

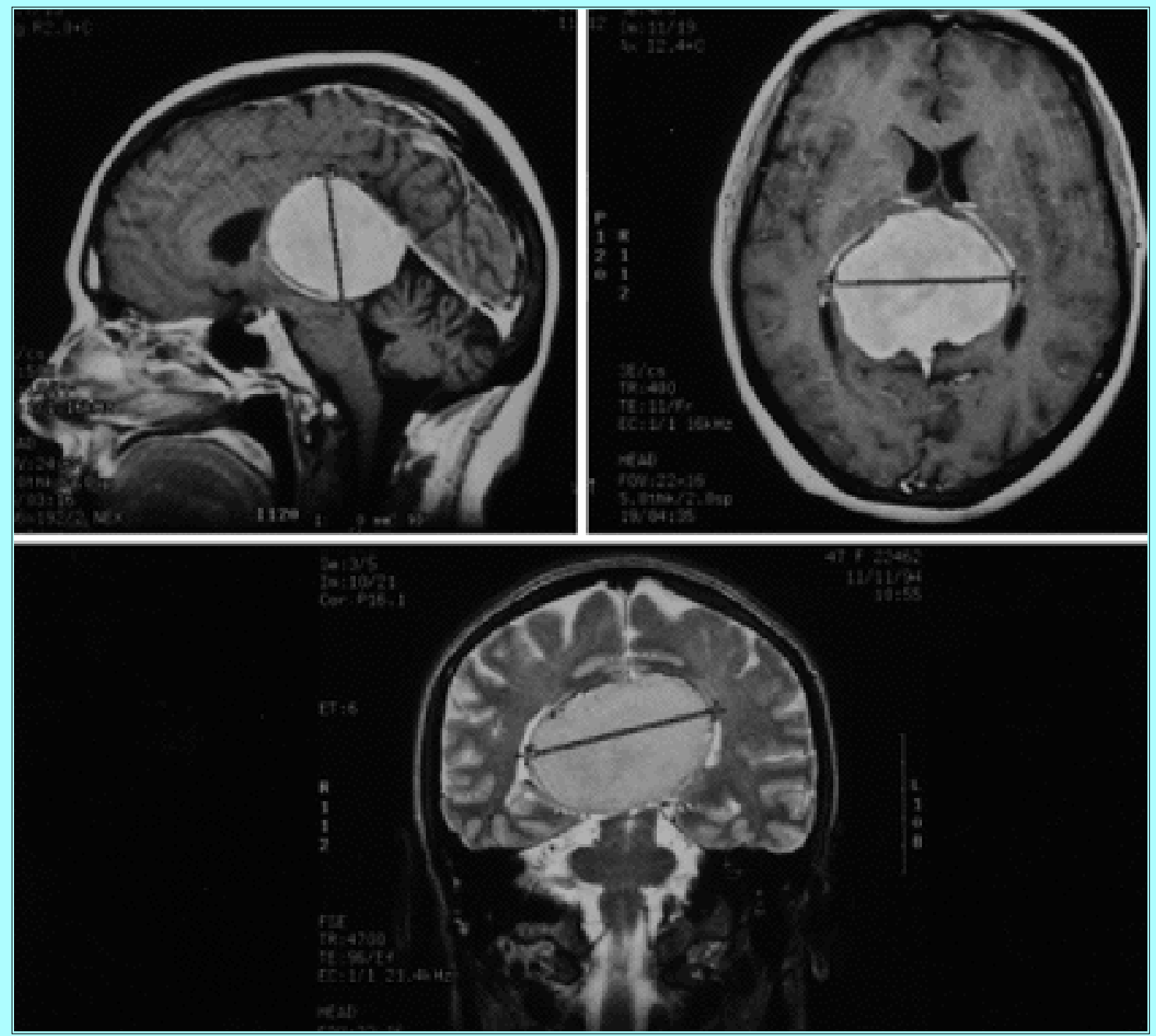

Fig. 4. Case 1. Sagittal and axial $\mathrm{T}_{1}$-weighted MR images (upper) obtained after gadolinium administration, and coronal $\mathrm{T}_{2}$-weighted MR images (lower) demonstrating a large pineal region mass with intense homogeneous contrast enhancement and increased signal intensity on the $\mathrm{T}_{2}$-weighted sequence.

\section{RESULTS}

Five patients underwent preoperative placement of a VP shunt. Preoperative embolization was performed in three patients who had tentorial meningiomas. The nondominant transverse sinus was on the left side in five cases and on the right side in one case (Table 1). In two patients an occipital-transtentorial approach was attempted, and in a third an infratentorial-supracerebellar approach was initially attempted. However, in all patients the combined approach was necessary to remove the tumor completely (Case 1, Figs. 4-6; Case 2, Figs. 7 and 8). 


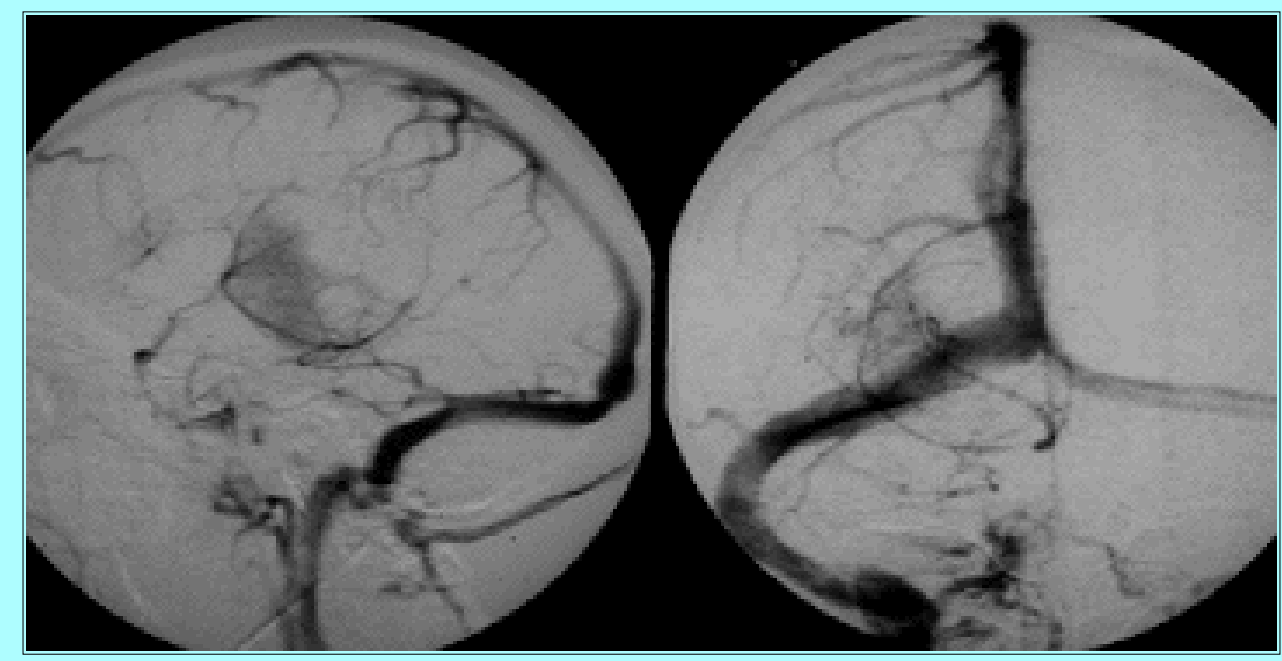

Fig. 5. Case 1. Venous phase of digital subtraction angiography of the right internal carotid artery injection in lateral (left) and anteroposterior (right) projections. A marked mass effect with downward displacement of internal cerebral veins is seen. The right transverse sinus is clearly the dominant side.
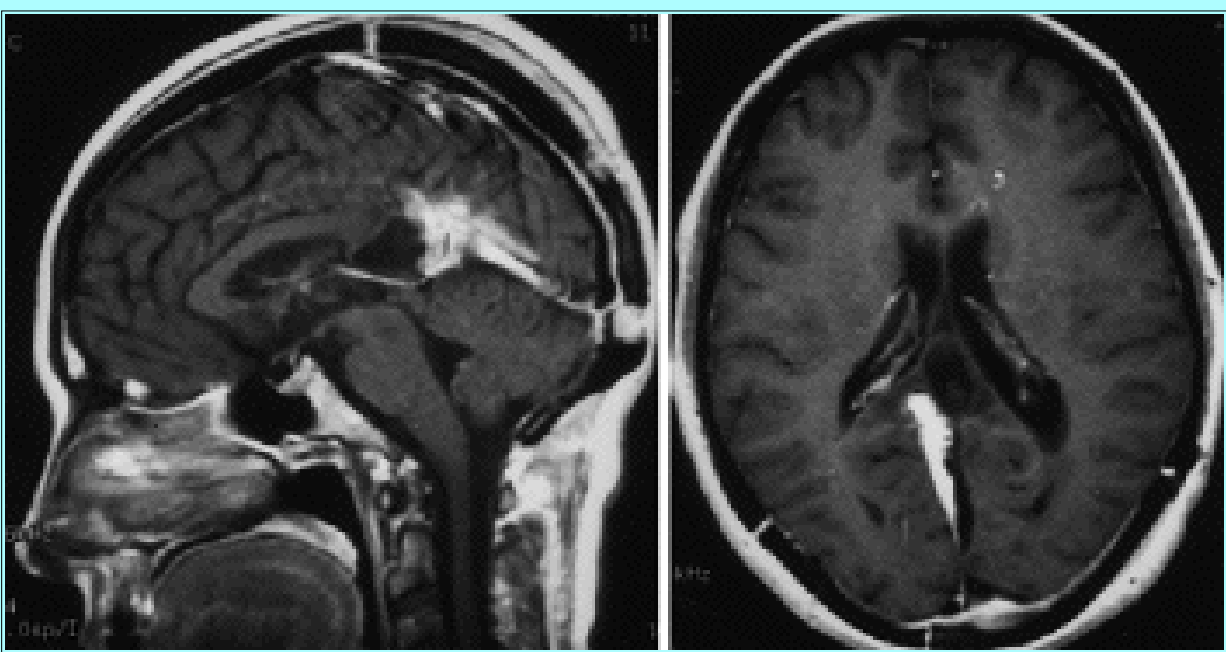

Fig. 6. Case 1. At the 3-month follow-up review sagittal and axial $\mathrm{T}_{1}$-weighted $\mathrm{MR}$ images obtained after gadolinium administration demonstrated no residual tumor. Dural enhancement is seen along the tentorium and involves postoperative changes in the pineal region.

One of the six patients suffered transient visual loss, and another had mild right sixth cranial nerve paresis; both recovered in 3 weeks. One patient required replacement of the VP shunt that had been inserted preoperatively. 


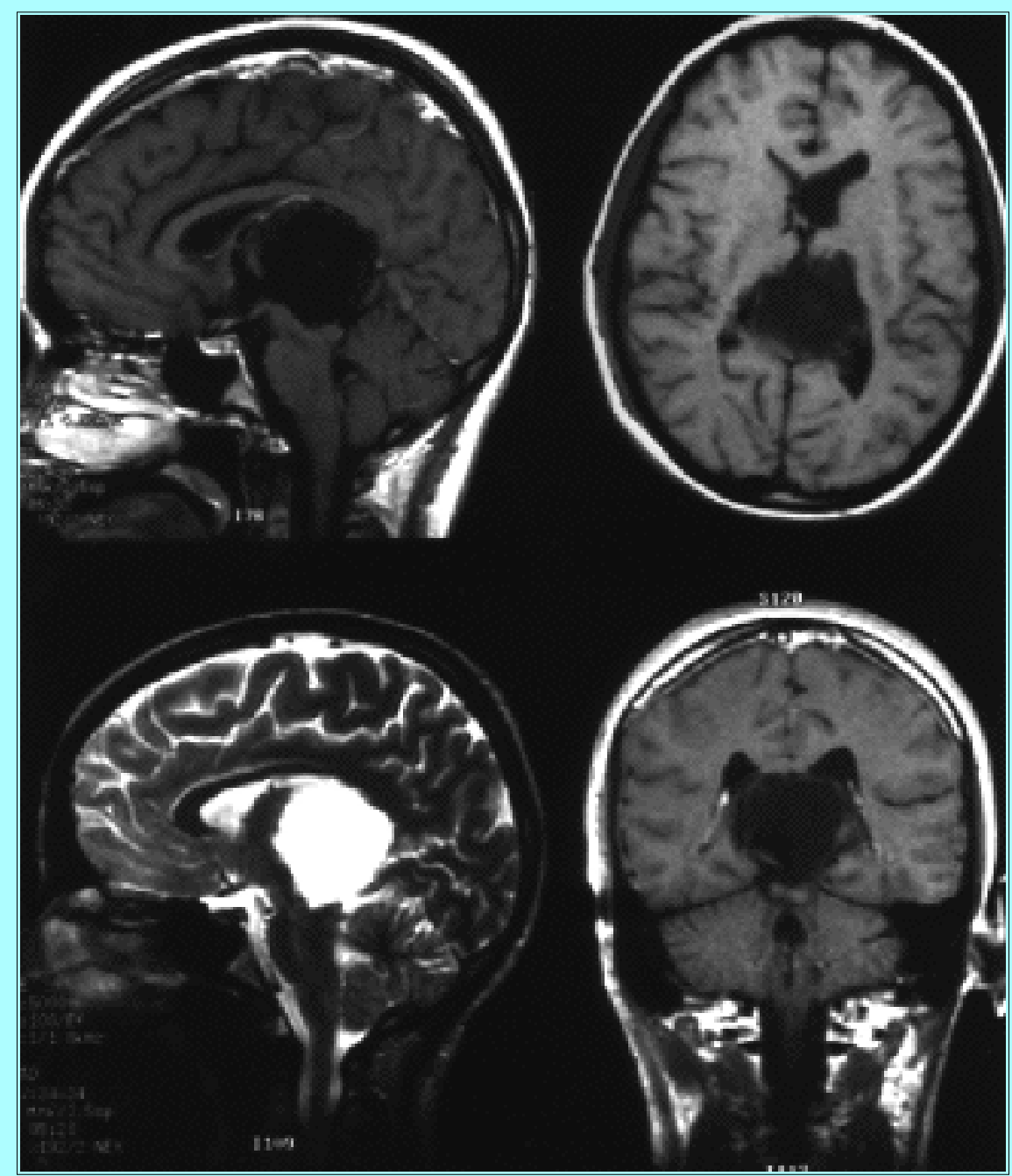

Fig. 7. Case 2. Preoperative MR images (clockwise from top left): sagittal $\mathrm{T}_{1}$ - postcontrast, axial $\mathrm{T}_{1^{-}}$, coronal $\mathrm{T}_{1^{-}}$- postcontrast, and sagittal $\mathrm{T}_{2}$-weighted studies demonstrating a pineal region tumor that follows the cerebrospinal fluid signal closely on $\mathrm{T}_{1}$ - and $\mathrm{T}_{2}$-weighted sequences. 


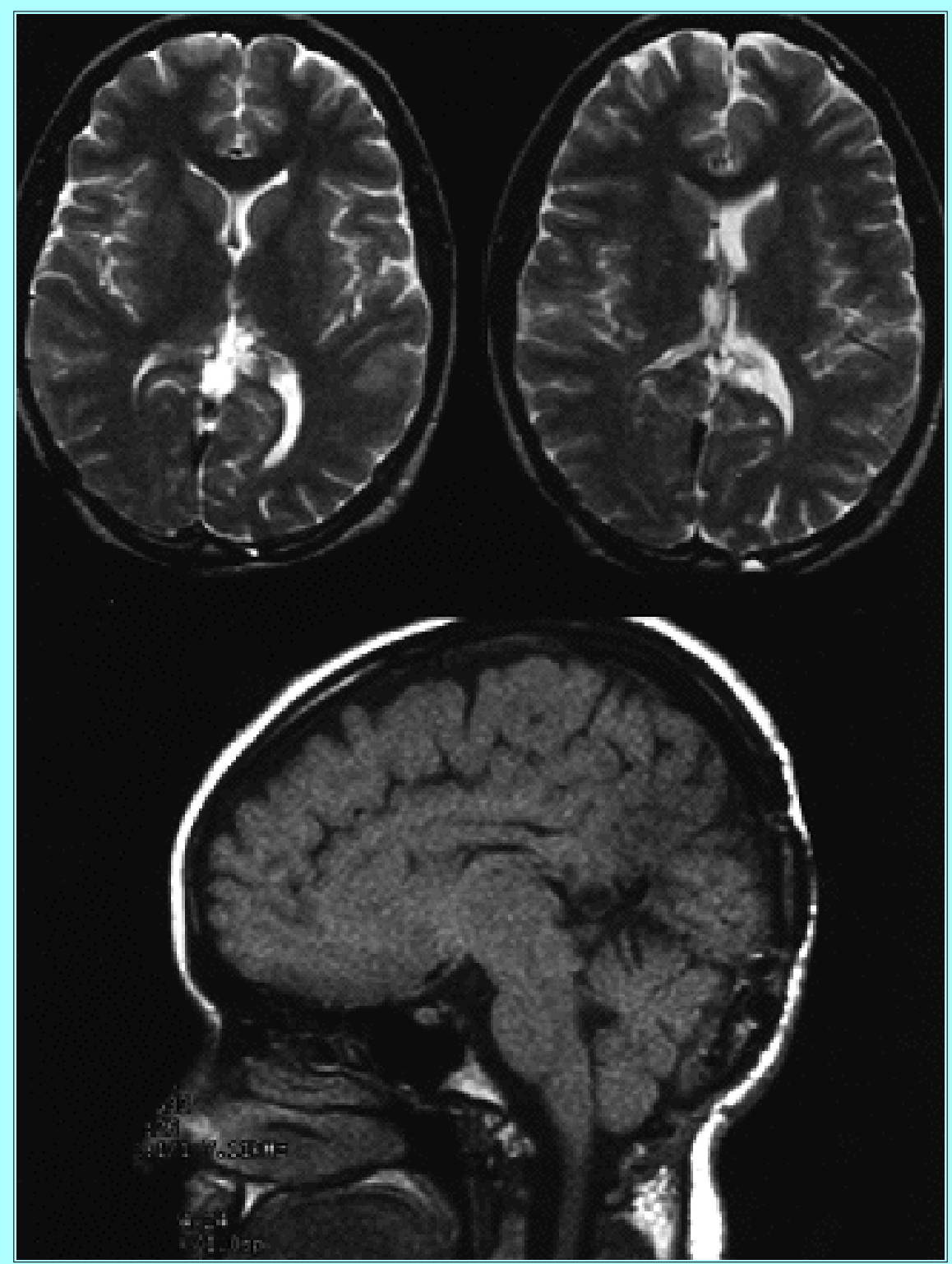

Fig. 8. Case 2. Axial $\mathrm{T}_{2}$ - and sagittal $\mathrm{T}_{1}$-weighted $\mathrm{MR}$ images obtained postoperatively demonstrating changes in the pineal region and no residual mass.

\section{Radiological Evaluation and Anatomical Study}

The projections of the main approaches for large pineal region tumors were studied using a midsagittal MR image. The retraction of the occipital lobe was imagined as a parallel line drawn $1.5 \mathrm{~cm}$ superior to the tentorium (straight sinus), with retraction of the cerebellum as a parallel line drawn $2 \mathrm{~cm}$ inferiorly. An MR image showed that the giant tentorial meningioma in our first patient (Case 1) had the maximum diameter of $5.1 \mathrm{~cm}$. The occipital-transtentorial approach had a projection revealing $65 \%$ of the tumor in the sagittal plane $(\mathrm{a}=3.3 \mathrm{~cm})$, and the infratentorial-supracerebellar approach had a projection of $76 \%(\mathrm{~b}$ $=3.9 \mathrm{~cm}$ ), which was larger than the first one. The projection of the combined supra/infratentorial-transsinus approach revealed the highest value as $100 \%(\mathrm{c}=5.1 \mathrm{~cm})$, and the wide working space provided for the surgeon was also demonstrated through this approach (Fig. 9). The measurement of the same values in our second patient (Case 2) also showed a ratio of $\mathrm{c}>\mathrm{b}>\mathrm{a}(\mathrm{c}=4.6$ $\mathrm{cm}, 100 \% ; \mathrm{b}=4.1 \mathrm{~cm}, 93 \%$; and $\mathrm{a}=2.8 \mathrm{~cm}, 60 \%$ ). 


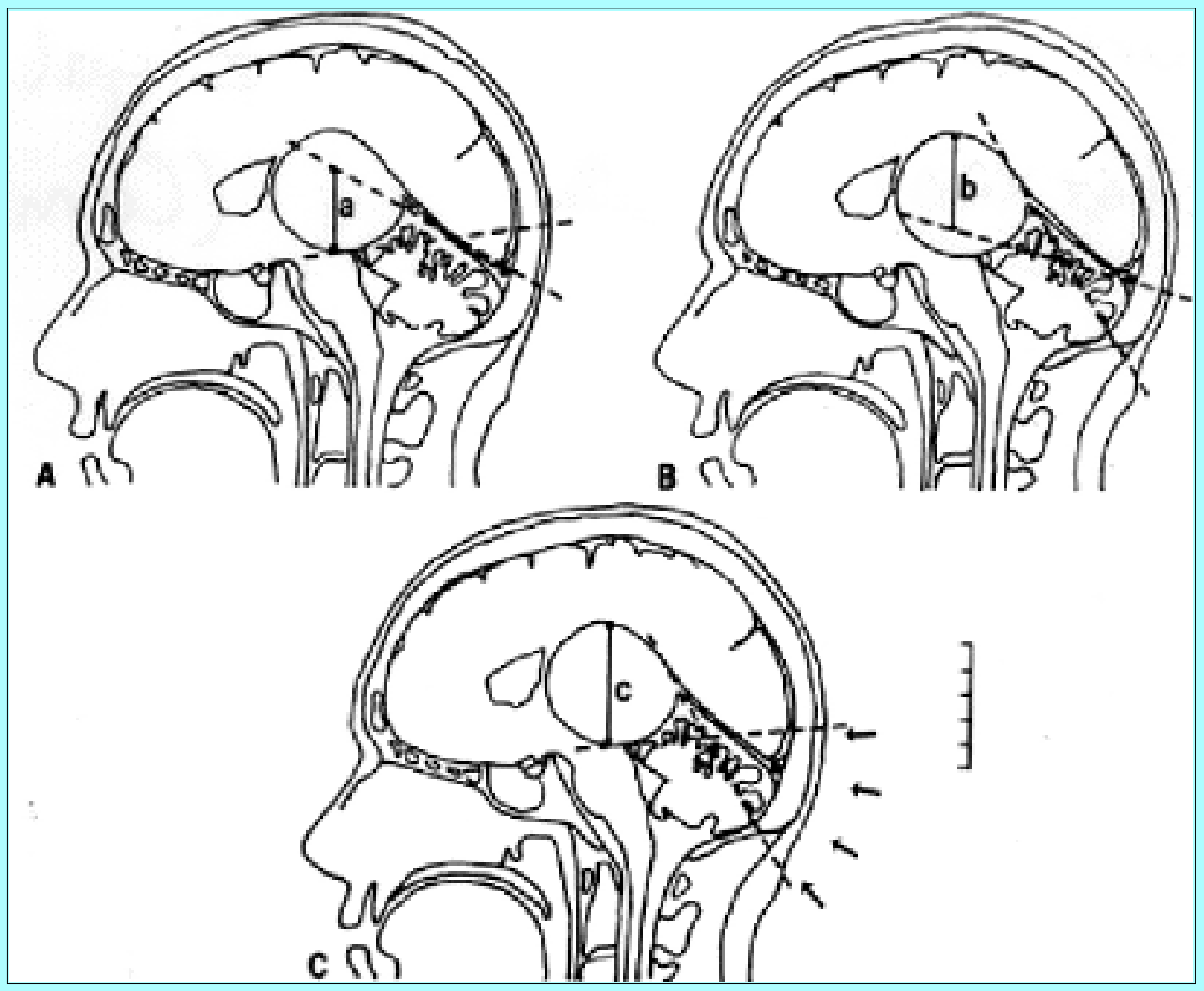

Fig. 9. Schematic drawings of midsagittal images demonstrating the exposure of the various approaches. A: The occipital-transtentorial approach with $1.5 \mathrm{~cm}$ of retraction on the occipital lobe allows $65 \%$ exposure of the pineal region mass $(\mathrm{a}=3.3 \mathrm{~cm})$. B: The infratentorial-supracerebellar approach with $2 \mathrm{~cm}$ of cerebellar retraction allows $76 \%$ exposure of the pineal region mass $(b=3.9 \mathrm{~cm}) . \mathrm{C}$ : Combined supra/infratentorial-transsinus approach allows $1.5 \mathrm{~cm}$ of occipital lobe and $2 \mathrm{~cm}$ of cerebellar retraction and $100 \%$ exposure of the same pineal region mass $(\mathrm{c}=5.1 \mathrm{~cm})$. The wide working space available to the surgeon with this approach is also demonstrated (arrows). Dashed lines indicate tumor exposure.

The surgical anatomy of the pineal region for the combined approach was studied in five cadaveric head specimens. We encountered no bridging veins between the transverse sinus and the inferior surface of the occipital lobe. However, the retraction of the cerebellum may result in the sacrifice of some small bridging veins. In all specimens we chose one side of the transverse sinus close to the torcular herophili and sectioned it. After the slight retraction of the occipital lobe and the cerebellum, the superior approach to the splenium of corpus callosum, the pineal gland and the third ventricle, and the lateral and inferior approach into the quadrigeminal cistern were large enough to expose the pineal region (Fig. 10). 


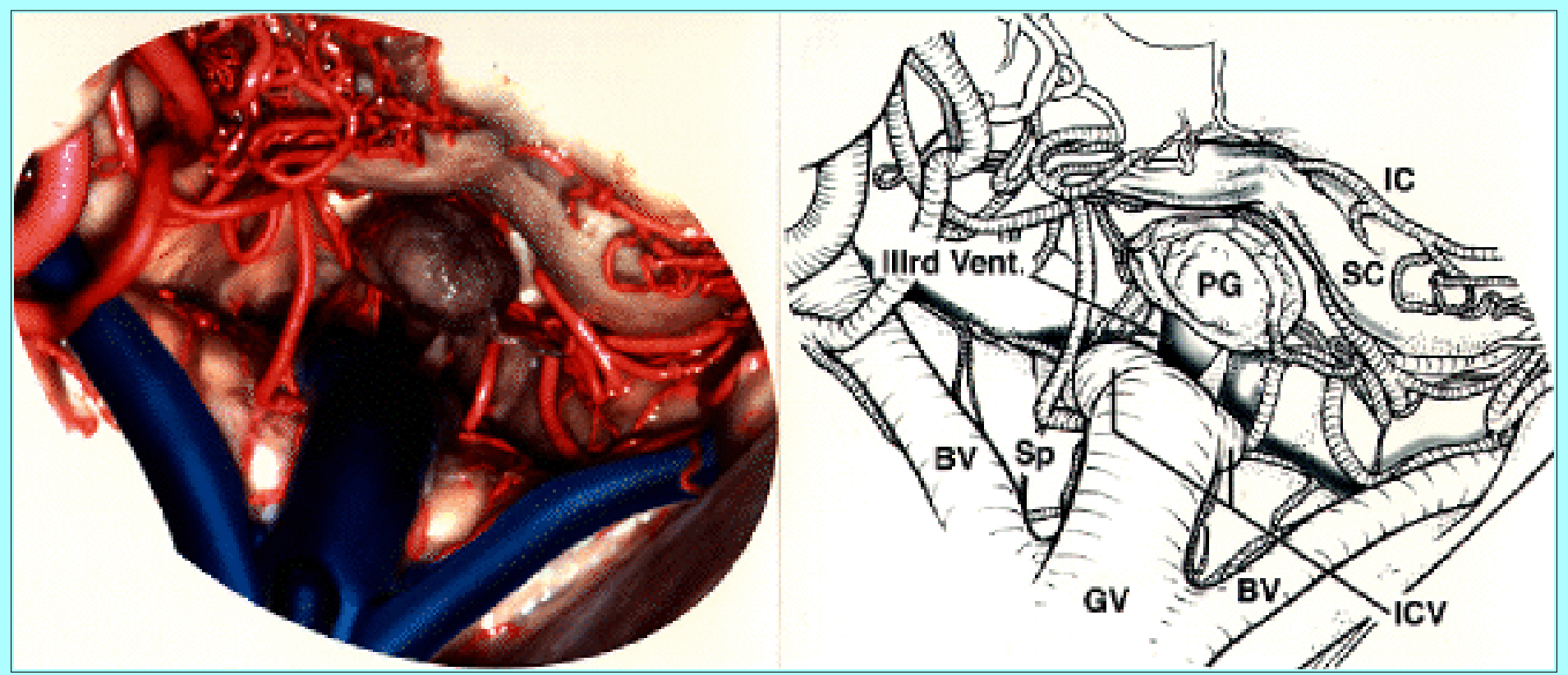

Fig. 10. Left: Photograph showing the wide exposure of the pineal region after a combined supra/infratentorial-transsinus approach in a cadaveric head specimen. Right: Artist's drawing of the anatomical structures. BV = basal vein of Rosenthal; GV = vein of Galen; IC $=$ inferior colliculus; ICV = internal cerebral vein; IIIrd Vent. = third ventricle; $\mathrm{PG}=$ pineal gland; $\mathrm{SC}=$ superior colliculus; $\mathrm{Sp}=$ splenium of the corpus callosum.

\section{DISCUSSION}

\section{Previous Attempts to Reach the Pineal Region}

Although Cushing[7] first proposed the idea of the surgical treatment of pineal lesions, he said that he had never succeeded in exploring a pineal tumor sufficiently to justify an attempt at removing it. Dandy[9] tried to remove pineal tumors via the transcallosal approach with the patient supine, splitting the corpus callosum and resecting 2 to $4 \mathrm{~cm}$ of the splenium. The dissection was extremely difficult to perform between the internal cerebral veins and the basal vein of Rosenthal and usually necessitated sacrificing the internal cerebral and superior cerebellar veins. Also, an occipital lobectomy was occasionally required.[22] Despite several complications and a mortality rate of $20 \%$, this technique was preferred by several authors.[12,14,18,32] The park-bench position was used in this approach, which brought the sagittal sinus into a horizontal orientation and allowed the brain to retract with the pull of gravity.[4]

Van Wagenen[34] used the transventricular approach in another unsuccessful attempt at removing pineal tumors.[24,32] He tried to make a 6- to 7-cm, reversed L-shaped incision in the cortex, extending from the posterior end of the superior temporal gyrus upward and backward, ending at the superior parietal lobule. With another incision he reached the lateral ventricle. This approach was not preferred and has rarely been used because of the morbidity resulting from the cortical incisions.[22]

\section{Infratentorial-Supracerebellar Approach}

The infratentorial-supracerebellar approach was introduced by Krause and improved by Stein[31] who used microsurgical techniques. It has been reported by many authors that this approach allowed easy orientation, did not require destruction of important structures, and provided for good visibility of the important veins. $[4,6,11,15,29-31]$ The sitting position was preferred so that the cerebellum could fall 
inferiorly, thereby giving a wider surgical view without accumulation of blood in the operating field.[15] The main disadvantage of this approach was the limited exposure of the tumors, which extended anteriorly into the third ventricle and above the deep venous complex.[4] Large tumors extending superiorly or inferiorly to the field of view can be brought into view by first debulking the tumor and then grasping the tumor capsule and moving it. However, this method does not always work, especially if the tumor is bloody. The lateral exposure of the tumor via an infratentorial-supracerebellar approach is also restricted.

It is well known that the sitting position entails the risk of air embolism for the patient and is uncomfortable for the surgeon.[2,15] Kobayashi, et al.,[16] described the Concorde position; a prone position that provides for the elevation of the patient's shoulders with the head tilted to the right, away from the surgeon. Although this position minimizes the risk of an air embolism and is more comfortable for the surgeon, it is very disadvantageous for an assistant.[2] A modified Concorde approach with the same disadvantage was reported by Bloomfield, et al.[4]

\section{Occipital-Transtentorial Approach}

After the description of the occipital-transtentorial approach was published,[12] some authors used it with slight modifications.[13,23,24] The sitting,[22-25] semisitting,[4] and prone[26] positions were usually preferred for this approach. Some authors also used a "three-quarter prone" position, concluding that it eliminated the main disadvantages of the sitting position. There was no risk of air embolism and the surgeon gained a better position from which to work.[2,5] The occipital lobe also fell, eliminating the need for retraction. However, this position entailed some difficulties in orientation. During the occipital-transtentorial approach a small part of the splenium might be sacrificed and the occipital lobe might be retracted, which could lead to a homonymous hemianopsia. The approach to the contralateral vein of Rosenthal was difficult.[2,4,17] The major advantages of this approach were the possibility of a larger exposure of the lesion and its helpfulness in dissection of the lateral extension of the tumor.[4]

The infratentorial-supracerebellar approach is usually chosen for tumors located below the deep venous complex in the pineal region. When the tumor is located above this complex or extends anteriorly into the third ventricle, the transcallosal approach is occasionally used. When the tumor is extended above and below this complex, the occipital-transtentorial approach is preferred. It has been suggested that the depth of the lesion is not a factor in choosing one approach over another. The major factors affecting the choice of approaches are the normal anatomical structures encountered in and around the tumor. These structures may be sacrificed to expose a wider angle and gain access to the entire tumor.[4] It is obvious that with gentle retraction the area between the undersurface of the occipital lobe and the upper surface of the cerebellum provides the largest exposure for giant pineal region lesions. This requires division of the transverse sinus, which should be completed at the nondominant side with the cutting of tentorium. The advantages and disadvantages of the main approaches used for resection of pineal region tumors are summarized in Table 2. 
TABLE 2

ADVANTAGES AND DISADYNTAGES OF THE MAIN SURGKAL APPROACHES TO PINEAL REGON TUMORS

$\begin{array}{ccc}\text { Irratentorial- } & \text { Occipital- } & \text { Suprafirfratentorial- } \\ \text { Suprace ebellar Approach } & \text { Transtertorial Approach } & \text { Transsinus Approach }\end{array}$

\section{aduan tiges}

cerebellum naturally fals

inferiorly w/gravity

easy orientation tridging veins between the medial occipital pole \& the transuerse sinus are usually absent

position com fortable for surgeon

\section{disaduan biges}

exposure is limited if distance between the collicular plate

$\&$ tentorial notch is small

possitility of multi ple draining

weins between the cerebellum

\& tentorium

limited exposure anteriorly of the

3rd wentricle \& above the deep

venous structures

sitting position: risk of air embo-

lism, fatigue for surgeon

\section{Combined Supra/Infratentorial-Transsinus Approach}

Combined approaches for different regions and lesions of the brain have been used by several authors.[1,3,10,19-21,28,33] The combined approach accomplished via a nondominant transverse sinus section and then a reanastomosis for a pineal region meningioma were reported by Sekhar and Goel.[27] Since that time we have used this approach for the removal of six large pineal region tumors. The patient's position was either semiprone or three-quarters prone and was comfortable for the surgeon and the assistant.

Previous attempts to remove tumors in three different patients by using the infratentorial-supracerebellar or occipital-transtentorial approach were unsuccessful. In our cases, the exposure of all lesions by using the combined approach was greater than with the other two approaches and substantially minimized the risks associated with retraction. The important venous structures of the galenic system were well exposed and none of them had to be sacrificed. The quadrigeminal cistern could be visualized between the pineal gland and cerebellum with no retraction of the cerebellum. The tentorium was a natural barrier for protecting the occipital cortex during the retraction. In tentorial meningiomas with a good arachnoid plane around the lesion, the total removal of the tumor was simpler.

We usually prefer to use the infratentorial-supracerebellar approach to resect tumors of the pineal region. The main indications for the use of the combined supra/infratentorial-transsinus approach in tumors are as follows: 1) large tumors with diameters greater than $4.5 \mathrm{~cm} ; 2$ ) tumors extending well above and below the planes of the tentorium or tumors arising from the tentorium; 3 ) tumors located well below the plane of cerebellar retraction; 4) tumors encasing important venous structures of the region; and 5) tumors that are very vascular, requiring the surgeon to cut around the tumor initially and devascularize it 
before performing internal debulking. Our radiological and anatomical studies and surgical experiences also confirmed that this approach provides a wider exposure for large pineal region tumors than the other two approaches.

\section{CONCLUSIONS}

The combined supra/infratentorial-transsinus approach provides the greatest exposure for large pineal region tumors and requires less brain retraction than either the infratentorial-supracerebellar or the occipital-transtentorial approach.

\section{Acknowledgments}

The authors express their gratitude to Jennifer Pryll for the medical illustrations and to Joseph Reister for editing and preparing the manuscript.

\section{References}

1. Al-Mefty O, Fox JL, Rifai A, et al: A combined infratemporal and posterior fossa approach for the removal of giant glomus tumors and chondrosarcomas. Surg Neurol 28:423-431, 1987

2. Ausman JI, Malik GM, Dujovny M, et al: Three-quarter prone approach to the pineal-tentorial region. Surg Neurol 29: 298-306, 1988

3. Bailey P: Concerning technic of operation for acoustic neurinoma. Zentralbl Neurochir 4:1-5, 1939

4. Bloomfield SM, Sonntag VKH, Spetzler RF: Pineal region lesions. BNI Q 1:10-23, 1985

5. Brotchi J, Raftopoulos C, Levivier M, et al: Lésions de la région pinéale et falco-tentorielle. Abord occipito-pariétal en trois-quarts ventral avec volet infra-sagittal. Neurochirurgie 37:410-415, 1991

6. Bruce JN, Stein BM: Surgical management of pineal region tumors. Acta Neurochir 134:130-135, 1995

7. Cushing H: Intracranial Tumors: Notes Upon a Series of 2000 Verified Cases With Surgical Mortality Pertaining Thereto. Springfield, Ill: Charles C. Thomas, 1932, p 64

8. Dandy WE: The Brain. Hagerstown, MD: WF Prior, 1966, p 590

9. Dandy WE: An operation for the removal of pineal tumors. Surg Gynecol Obstet 33:113-119, 1921

10. Daspit CP, Spetzler RF, Pappas CTE: Combined approach for lesions involving the cerebellopontine angle and skull base: experience with 20 cases--preliminary report. Otolaryngol Head Neck Surg 105:788-796, 1991

11. Herrmann HD, Winkler D, Westphal M: Treatment of tumours of the pineal region and posterior part of the third ventricle. Acta Neurochir 116:137-146, 1992

12. Horrax G: Treatment of tumors of the pineal body. Experience in a series of twenty-two cases. Arch Neurol Psychiatry 64:227-242, 1950

13. Jamieson KG: Excision of pineal tumors. J Neurosurg 35:550-553, 1971 
14. Kahn EA: Surgical treatment of pineal tumor. Arch Neurol Psychiatry 38:833-842, 1937

15. Kanno T: Surgical pitfalls in pinealoma surgery. Minim Invasive Neurosurg 38:153-157, 1995

16. Kobayashi S, Sugita K, Tanaka Y, et al: Infratentorial approach to the pineal region in the prone position: Concorde position. Technical note. J Neurosurg 58:141-143, 1983

17. Konovalov AN, Spallone A, Pitzkhelauri DI: Meningioma of the pineal region: a surgical series of 10 cases. J Neurosurg 85:586-590, 1996

18. Kunicki A: Operative experiences in 8 cases of pineal tumor. J Neurosurg 17:815-823, 1960

19. Lazar ML, Clark K: Direct surgical management of masses in the region of the vein of Galen. Surg Neurol 2:17-21, 1974

20. Malis LI: Surgical resection of tumors of the skull base, in Wilkins RH, Rengachary SS (eds): Neurosurgery. New York: McGraw-Hill, 1985, Vol 1, pp 1011-1021

21. Naffziger HC: Brain surgery. With special reference to exposure of the brain stem and posterior fossa: the principle of intracranial decompression, and relief of impactions in the posterior fossa. Surg Gynecol Obstet 46:241-248, 1928

22. Pendl G: The surgery of pineal lesions--historical perspective, in Neuwelt AE (ed): Diagnosis and Treatment of Pineal Region Tumors. Baltimore: Williams \& Wilkins, 1984, pp 139-154

23. Poppen JL: The right occipital approach to a pinealoma. J Neurosurg 25:706-710, 1966

24. Poppen JL, Marino R Jr: Pinealomas and tumors of the posterior portion of the third ventricle. $\mathbf{J}$ Neurosurg 28:357-364, 1968

25. Reid WS, Clark WK: Comparison of the infratentorial and transtentorial approaches to the pineal region. Neurosurgery 3:1-8, 1978

26. Sano K: Pineal region tumors: problems in pathology and treatment. Clin Neurosurg 30:59-91, 1983 27. Sekhar LN, Goel A: Combined supratentorial and infratentorial approach to large pineal-region meningioma. Surg Neurol 37:197-201, 1992

28. Spetzler RF, Daspit P, Pappas CTE: The combined supra- and infratentorial approach for lesions of the petrous and clival regions: experience with 46 cases. J Neurosurg 76:588-599, 1992

29. Stein BM: The infratentorial supracerebellar approach to pineal lesions. J Neurosurg 35:197-202, 1971

30. Stein BM: Supracerebellar-infratentorial approach to pineal tumors. Surg Neurol 11:331-337, 1979

31. Stein BM: Surgical treatment of pineal tumors. Clin Neurosurg 26:490-510, 1979

32. Suzuki J, Iwabuchi T: Surgical removal of pineal tumors. (Pinealomas and teratomas.) Experience in a series of 19 cases. J Neurosurg 23:565-571, 1965

33. Symon L: Surgical approaches to the tentorial hiatus. Adv Tech Stand Neurosurg 9:69-112, 1982 
34. Van Wagenen WP: A surgical approach for the removal of certain pineal tumors. Report of a case. Surg Gynecol Obstet 53:216-220, 1931

35. Wisoff JH, Epstein F: Surgical management of symptomatic pineal cysts. J Neurosurg 77:896-900, 1992

Manuscript received August 1, 1997.

Accepted in final form January 6, 1998.

Address reprint requests to: Laligam N. Sekhar, M.D., Department of Neurological Surgery, The George Washington University Medical Center, 2150 Pennsylvania Avenue NW, Suite 7-420, Washington, D.C. 20037. 